\title{
Processos de subjetivação de professores de inglês na contemporaneidade
}

\author{
Ana Júlia Monteiro de Assis ${ }^{1}$ \\ Marco Antônio Margarido Costa ${ }^{2}$
}

\begin{abstract}
Resumo: Este trabalho apresenta os resultados de uma pesquisa (PIBIC CNPq 2014-2015) que investigou os processos de subjetivação de professores de inglês na contemporaneidade, à luz da Análise de Discurso de orientação pecheutiana (2009) e de sua vertente brasileira, desenvolvida inicialmente por Orlandi $(2005,2006,2007)$. Para tanto, nosso objetivo foi estudar a discursividade em torno da formação de professores de inglês, buscando compreender quais discursos mostramse de forma mais evidente nesses processos de subjetivação e que consequências trazem para a formação docente e para constituição de suas identidades. $\mathrm{Na}$ análise, observamos a predominância de um professor constituído principalmente pela falta (de preparo, de conhecimentos linguísticos e/ou teóricos, de prática, etc.), evidenciada em diferentes tipos de discursos (didático-pedagógico, ensino-aprendizagem, científico, político educacional e instrucional). Constatamos que essa "falta" está cada vez mais presente na formação de professores de inglês, uma vez que os processos de objetivação/subjetivação do sujeito professor parecem reforçar esse discurso, e os restringirem do processo constante de transformação, em que o sujeito assumiria identidades diferentes, em diferentes momentos, sempre em busca da completude. A partir desta pesquisa, pudemos estudar mais um ângulo por meio do qual é possível conhecer os cursos de licenciatura e ressaltar o papel da universidade pública na formação de professores e no desenvolvimento de pesquisas.
\end{abstract}

Palavras-chave: Formação de professores de inglês; Discurso; Processos de subjetivação.

\section{English teachers' processes of subjectification nowadays}

\begin{abstract}
Based on Pêcheux's theoretical and philosophical concepts of Discourse Analysis (2009) and Orlandi $(2005,2006,2007)$, who initially developed his field of study in Brazil, this study presents the results of a research (PIBIC CNPq 2014-2015) that investigated the processes of subjectivation of English teachers nowadays. Our aim was to study the discursivity in English teacher education, seeking to understand which discourses were more evinced in the processes of subjectivation of English teachers and what consequences they bring to their education and to the constitution of their identities. The analysis revealed the predominance of a teacher consisting mainly by absence (of preparation, linguistic and/or theoretical knowledge, practice, etc.), evidenced by different types of discourses (didactic and pedagogical, teaching and learning, scientific, educational and instructional). We found out that this "absence" is increasingly present in the English teachers' education, since the processes of objectivation/ subjectivation of the teacher seem to reinforce this discourse, and restrict
\end{abstract}

${ }^{1}$ Graduanda em Letras Língua Inglesa, Unidade Acadêmica de Letras, UFCG, Campina Grande, PB, Email: aninhatarquino@gmail.com

${ }^{2}$ Professor Doutor da Unidade Acadêmica de Letras. Atuando no Programa de Pós-Graduação em Linguagem e Ensino, UFCG, Campina Grande, PB, E-mail: marcoantoniomcosta@gmail.com 


\section{Revista Letras Raras}

ISSN: 2317-2347 - Vol, 7, Ano 4, No 2 - 2015

the constant process of transformation, in which the subject would assume different identities at different times, always in search of completeness. From this research, we could study a new perspective through which it is possible to know undergraduation courses and highlight the role of public universities in teacher education and in the development of research.

Keywords: Teacher education; Discourse; Processes of subjectivation.

\section{INTRODUÇÃO}

Em pesquisa anterior (PIBIC CNPq 2013-2014), estudamos projetos realizados no âmbito do estágio docente apresentados no livro "Projetos e Práticas na Formação de Professores de Língua Inglesa", organizado por Medrado e Reichmann (2012).

Ao analisarmos a discursividade acerca da formação do professor de inglês, foi possível detectar que os trabalhos reunidos no referido livro podem ser categorizados em três grandes eixos por meio dos quais se pode refletir sobre a formação desse docente. $\mathrm{O}$ primeiro eixo diz respeito às mudanças curriculares promulgadas em leis e diretrizes para os cursos de licenciatura. Com o advento de novos recursos tecnológicos na sociedade contemporânea, faz-se também necessário pensar sobre novas práticas de letramento nos cursos de formação de professores esse é o foco do segundo eixo. Por fim, o terceiro eixo aborda a questão da construção de uma nova profissionalidade docente, a partir da noção de gênero profissional, que é composto por um conjunto de ações, recursos e rotinas do trabalho do professor.

Com o desenvolvimento da pesquisa, pudemos observar que os três eixos mencionados abordam uma questão que nos parece central: a constituição da identidade do professor de inglês. Propostas de mudanças curriculares, de novas práticas de letramento e de novas características profissionais envolvem diretamente a maneira como esse professor de inglês se reconhece como tal. Por isso, esta pesquisa se justifica, uma vez que se faz premente estudar os diferentes modos de subjetivação que essas mudanças curriculares e essas práticas de letramento acarretam na constituição da formação docente. 


\section{Revista Letras Raras}

ISSN: 2317-2347 - Vol. 7, Ano 4, No 2 - 2015

Considerando os resultados apontados, mostrou-se relevante pesquisar a constituição da identidade do professor de inglês com o objetivo de compreender de que maneira os processos descritos provocam deslocamentos na forma como professores de inglês se veem na contemporaneidade. Por essa razão, essa pesquisa (PIBIC CNPq 2014-2015) investigou, especificamente, como os diferentes discursos estudados constroem posições subjetivas que o sujeito professor de inglês pode "ocupar" e quais as consequências e ou implicações disso na formação desse profissional.

Com o intuito de estudar os processos de subjetivação de professores de inglês, nossa pesquisa teve como objeto de análise, o livro "Língua, discurso e processos de subjetivação na contemporaneidade" (CARMAGNANI; GRIGOLETTO, 2013) que tem como propósito trazer à discussão questões relativas à influência de diversos espaços discursivos na constituição identitária do professor na contemporaneidade. O livro reúne quinze textos que se subdividem em quatro seções: 1- língua e subjetividade: espaços teóricos; 2- discursos sobre educação, professores e ensino de línguas; 3- reflexões sobre os processos de ensino e aprendizagem de língua estrangeira; e 4- olhares sobre sujeitos na contemporaneidade.

O foco de análise concentra-se no estudo das segunda e terceira seções do livro, que trazem discussões com foco na educação, nos professores e no ensino de língua; e que apresentam análises sobre o processo de ensino e aprendizagem de línguas estrangeiras, respectivamente. Tais seções foram escolhidas para constituição de nosso corpus, juntamente com o texto que encerra a primeira seção do livro, por apresentarem trabalhos constituídos por análises, que melhor evidenciam os discursos que perpassam a formação docente e constroem posições subjetivas que o sujeito professor de inglês pode "ocupar".

Os demais textos da primeira seção do livro, que privilegiam a reflexão teórica sobre língua e subjetividade, nos ajudaram na compreensão e na composição do 


\section{Revista Letras Raras}

ISSN: 2317-2347 - Vol. 7, Ano 4, No 2 - 2015

painel teórico de nossa pesquisa (através das concepções de sujeito e de processos de subjetivação). Entretanto, a última seção do livro, por lançar olhares diversos sobre sujeitos e processos de subjetivação, sem evidenciar o professor ou a formação docente, não foi considerada em nossa análise.

Buscamos identificar qual(is) o(s) tipo(s) de discurso(s) que se fazem presentes em cada um dos referidos textos e em seguida, observamos e identificamos as categorias de análise de cada pesquisa, e o que cada uma delas revelava sobre o sujeito professor de inglês. Por fim, buscamos as reflexões de Foucault $(2003,2005)$ para observar como ocorrem os processos de subjetivação e de objetivação nesses estudos selecionados.

Ao passo que assim fizemos, iniciamos, portanto, segundo a metodologia da linha de análise do discurso adotada, o estudo desse material transformando-o de material bruto em corpus discursivo, que pela ótica da análise do discurso é construção do analista, que, a partir das perguntas que elabora inicialmente, promove a passagem da superfície linguística ao objeto discursivo e deste, ao processo discursivo (ORLANDI, 2005).

Com isso, visou-se compreender o modo de funcionamento do discurso pesquisado, na relação deste com o seu exterior discursivo (o interdiscurso). Em outras palavras, compreender o modo de funcionamento do discurso pesquisado significa identificar como esse discurso específico (da formação de professores de inglês) entra em relação com diferentes regiões do interdiscurso (memória do dizer). Ou, como argumentam Coracini e Ghiraldelo (2011), uma investigação que se volte para o interdiscurso busca identificar diferentes vozes que se cruzam ou traços que se mesclam na formação de um imaginário, o qual nos permite ver o que somos a partir do olhar do outro.

$\mathrm{Na}$ análise buscamos enfatizar os processos de subjetivação que afetam professores de língua inglesa, pré ou em serviço. Desse modo, as perguntas norteadoras para a análise foram: a) quais discursos mostram-se de forma mais 


\section{Revista Letras Raras}

ISSN: 2317-2347 - Vol. 7, Ano 4, No 2 - 2015

evidente nos processos de subjetivação do professor de inglês? e b) que consequências tais processos de subjetivação trazem para a formação desses professores?

Investigar e compreender os sentidos da formação de professores de inglês, nesse contexto, justifica-se não só como mais um ângulo por meio do qual se pode conhecer os cursos de licenciatura, mas também como forma de ressaltar o papel da universidade pública na formação de professores e no desenvolvimento de pesquisas.

\section{FUNDAMENTAÇÃO TEÓRICA}

Propomo-nos a analisar o presente corpus à luz da Análise de Discurso (AD) de orientação pecheutiana, como também mobilizamos conceitos de Foucault (2005, 2003a-d) que julgamos relevantes para nossa investigação. Acreditamos que essa perspectiva teórica e filosófica nos ajuda a pensar sobre a maneira como a materialidade linguística reflete o discurso (e, por conseguinte, a ideologia), revelando a aparente unidade dos discursos, ou conforme propõe Orlandi (2005, p. 72), uma das precursoras da AD no Brasil, a tarefa do analista é ver "como o discurso se textualiza".

Para essa pesquisadora, a $\mathrm{AD}$ "teoriza a interpretação, isto é, coloca a interpretação em questão" (2005, p. 25). Sendo assim, a partir do texto, deve-se buscar compreender o processo de produção de sentidos que a ausência de transparência da língua(gem) possibilita resgatar. Sobre esse aspecto, vale destacar reflexão de Brandão (1998, p. 19), que afirma que a $\mathrm{AD}$ concentra-se no texto, considerando a sua opacidade, levando em conta "o modo de funcionamento linguístico-textual dos discursos, as diferentes modalidades do exercício da língua num determinado contexto histórico-social de produção".

Desse modo, faz-se necessário apresentar, brevemente, algumas noções e conceitos da $\mathrm{AD}$ que compõem o painel teórico de referência que fundamentará 


\section{Revista Letras Raras}

ISSN: 2317-2347 - Vol, 7, Ano 4, N0 2 - 2015

nossa análise. Iniciamos com a noção de sujeito, e por meio dela, a de ideologia. De acordo com Pêcheux (2009, p. 133), o sujeito é constituído por um processo de "imposição/dissimulação" que o situa, outrossim, cria um significado para ele do que ele é e, ao mesmo tempo, o torna assujeitado a essa situação, constituindo, dessa forma, uma ilusão de que ele "funciona" por si mesmo. Ou seja, não se trata de um sujeito dotado de unicidade e consciência com domínio sobre seu dizer e sobre o sentido desse dizer. Disso decorre a noção de ideologia que, para a $\mathrm{AD}$, é uma formação imaginária, uma condição necessária que faz com que o sujeito e os

sentidos se constituam da maneira que se apresentam. É por meio dessa ideologia que o sujeito se vê, vê o outro, vê o objeto do qual fala e, notadamente, vê o lugar de onde ele e o outro falam. Enfim, é uma imagem que se constrói das "reais" condições de existência. Conforme explicita Orlandi (2007, p. 17), Pêcheux vê o discurso como "o lugar de contato entre língua e ideologia".

Buscamos em Foucault, cujas reflexões, segundo Brandão (2012, p. 31), "colocam diretrizes para uma análise do discurso", a noção de formação discursiva (FD). Esse conceito estabelece que o discurso é constituído por uma "dispersão" de enunciados. Isso auxilia o analista de discurso a perceber formulações diversas conjugando-se a fim de constituir um "novo" discurso, ou seja, um "novo" conjunto de enunciados.

Conforme apontam Charaudeau e Maingueneau (2004), foi Pêcheux o responsável por trazer a noção de FD para a AD. Para ele, toda formação social, isto é, uma relação entre as classes sociais, é constituída de posições políticas e ideológicas que se organizam em uma ou várias formações discursivas interligadas. São essas formações discursivas que estabelecem "o que pode e deve ser dito" a partir de uma posição dada em uma determinada conjuntura (PÊCHEUX, 2009, p. 160). Para formular essa teoria, Pêcheux parte do princípio de que o sentido de uma palavra não existe "em si mesmo". Decorre daí a noção de que não há um sentido fixo para as palavras, ele é determinado pela conjuntura sócio histórica na qual elas 


\section{Revista Letras Raras}

ISSN: 2317-2347 - Vol. 7, Ano 4, No 2 - 2015

são produzidas. O exterior linguístico (condições de produção do discurso) também afeta a linguagem, isto é, os sentidos das palavras são produzidos/determinados pela história. É por isso que para ele, o discurso é efeito de sentido entre locutores.

Com isso, para a AD, a linguagem é vista como produto histórico-social, sendo seu modo de funcionamento fator importante para uma perspectiva discursiva. De acordo com as palavras de Orlandi (2006, p. 117), “esse modo de funcionamento não é integralmente linguístico, uma vez que dele fazem parte as condições de produção, que representam o mecanismo de situar os protagonistas e o objeto do discurso".

Encontramos, ainda, em Pêcheux (2009, p. 162), a exploração de um conceito extremamente importante para a AD: o interdiscurso. Sua tese é de que as formações discursivas são constituídas em um espaço no qual figuram formações ideológicas diversas que estão permanentemente em relação de "desigualdade-contradiçãosubordinação", formando um "todo complexo com dominante". Em outras palavras, é por meio do interdiscurso que podemos identificar algo que já foi dito antes, em um local diferente, em um momento diferente. Devolvendo a palavra a Orlandi (2005), o interdiscurso é, desse modo, a memória do dizer.

Retomamos Foucault, cujas reflexões tinham como objetivo "esboçar uma história das diferentes maneiras nas quais os homens, em nossa cultura, elaboram um saber sobre eles mesmos" (NASCIMENTO; NEVES, 1994, p. 16), para observar os três modos pelos quais os seres humanos são transformados em sujeitos em nossa cultura (GRIGOLETTO, 2007).

O primeiro diz respeito à transformação do sujeito em objeto de estudo partindo, portanto, de uma ótica "objetificante". No segundo, a objetivação se dá pelo que Grigoletto (2007, p. 453) define como "práticas divididas e classificatórias, que separam e separaram, os sujeitos uns dos outros". E o terceiro, concerne ao estudo das técnicas de si, também chamadas de tecnologias do eu, em que o ser humano contribui para sua própria subjetivação. 


\section{Revista Letras Raras}

ISSN: 2317-2347 - Vol. 7, Ano 4, No 2 - 2015

Ainda segundo a pesquisadora, tais formas de subjetivação estão atreladas a diferentes formas de poder que exercem um importante papel na objetivação dos sujeitos. Há, portanto dois sentidos para o termo sujeito, um é "a subjetivação a alguém por controle e dependência" e o outro: "a subjetivação a sua própria identidade, pela consciência e autoconhecimento" (op. cit., p. 453). Como veremos a seguir, o primeiro sentido se aplica aos dois primeiros processos de objetivação, enquanto que o segundo sentido diz respeito ao terceiro processo de objetivação.

O primeiro processo de objetivação pode se dar pela comparação porque à medida que se comparam os itens envolvidos (transformando-os em objeto de estudo comparativo), colocam-no em uma grade classificatória, implicando em uma hierarquia. A posição subjetiva é instaurada, na medida em que permite a identificação dos sujeitos, pela tomada de posição no discurso.

O segundo processo de objetivação proposto por Foucault parte do princípio das tecnologias de vigilância e dominação, que pressupõe o controle, a homogeneização e a disciplinarização dos sujeitos pelas práticas sociais.

Por fim, o terceiro processo parte dos estudos das tecnologias do eu, que se trata de processos de (auto) subjetivação que os indivíduos aplicam a si mesmos, à proporção que falam de si mesmos (descrevem-se ou narram-se), e assim veem-se e analisam-se. Estão submetidos, igualmente, a mecanismos de controle e disciplina para agir e pensar sobre si.

Segundo Woodward (2000, p. 55) "a subjetividade sugere a compreensão que temos sobre o nosso eu", envolvendo os pensamentos e emoções conscientes e inconscientes que constroem nossas concepções sobre quem somos. Conforme a mesma autora, o conceito de subjetividade permite a exploração de sentimentos envolvidos no processo de produção de identidade e do investimento pessoal que fazemos em posições específicas de identidade, pois essa subjetividade é vivida em um contexto social envolvido pela linguagem e cultura que dão significado à experiência que temos de nós mesmos nos fazendo adotar uma identidade: 
os sujeitos são assim, assujeitados ao discurso e devem, eles próprios, assumi-lo como indivíduos que, dessa forma, se posicionam a si próprios. As posições que assumimos e com as quais nos identificamos constituem nossas identidades (WOODWARD, 2000, p. $55)$.

Há, portanto, entre discurso e identidade uma ligação bastante estreita. Tal fato leva-nos a afirmar que assumimos posições identitárias - que são, na verdade, frutos de movimentos de identificação, sempre instáveis e incompletos - pelo trabalho de interpelação dos discursos sobre nós (MITTMANN et al., 2008; MAGALHÃES et al., 2006). Sendo assim, em relação à constituição de identidade, tomaremos por base uma concepção de sujeito atravessado pela alteridade e, portanto, distanciado do conceito de sujeito intencional.

Trata-se de uma perspectiva que podemos denominar sociológica, uma vez que se parte da noção de que o sujeito constrói uma identidade para si a partir da sua inserção em uma determinada sociedade. Concebe-se então não um conceito sociológico clássico de identidade fixa, unificada e estável, mas sim um sujeito "pósmoderno", como uma figura caracterizada fundamentalmente pela fragmentação e instabilidade. Desse modo, a identidade passa a ser vista como "uma 'celebração móvel': formada e transformada continuamente em relação às formas pelas quais somos representados ou interpelados nos sistemas culturais que nos rodeiam" (HALL, 2006, p. 13). A instabilidade e a heterogeneidade do sujeito pós-moderno são postuladas não só como fruto de mudanças sociais, mas também pelo fato de essa perspectiva levar em conta uma estrutura simbólica fundamental entre sujeito e linguagem.

A presente pesquisa se inscreve, portanto, nessa linha teórica que acabamos de esboçar, que nos ajudou a melhor compreender o funcionamento da discursividade nos processos de subjetivação e constituição da identidade do sujeito professor de inglês em nossa análise. 


\section{PROCESSOS DE SUBJETIVAÇÃO DO PROFESSOR DE INGLÊS}

Nessa seção, seguem os objetivos dos referidos textos, seguidos das categorias de análise, dos tipos de discursos estudados e das concepções de sujeito que emergem através de cada pesquisa. Em seguida, apontamos pela perspectiva de Foucault, apresentada anteriormente, como os indivíduos são transformados em objetos de estudo através da objetivação, e é a partir dos três modos de objetivação, também apontados anteriormente, que as pesquisas estão apresentadas a seguir.

\subsection{Objetivação pela comparação}

Iniciamos a análise desse processo de objetivação com o estudo de Carmagnani (2013) que tem por objetivo analisar a representação da escola e de línguas estrangeiras na mídia impressa brasileira e sua relação com o discurso oficial sobre o ensino de línguas na escola, defendido nas Orientações Curriculares para o Ensino Médio (OCEM).

O mecanismo analítico utilizado pela pesquisadora é a retomada de enunciados produzidos pela mídia, presentes em textos que retratam a escola e o ensino de línguas, em revistas semanais. Desse modo, a pesquisadora estuda o discurso midiático e o discurso político-educacional.

Pelo viés do discurso midiático há uma ressonância de enunciados que replicam o discurso publicitário das escolas de idiomas, que apontam o aprendizado de inglês como equivalente ao sucesso no mercado de trabalho e à sobrevivência no mundo globalizado.

No que diz respeito ao sujeito professor, o mecanismo de retomada aponta evidências de um sujeito "lacunado", constituído pela falta de teorias, que traduzem a necessidade da busca incessante por uma formação continuada, que supostamente 


\section{Revista Letras Raras}

ISSN: 2317-2347 - Vol. 7, Ano 4, N0 2 - 2015

supriria essa falta que parece fadar ao fracasso e a mediocridade que aparentemente caracterizam a rede pública de ensino:

[...] esses enunciados apontam para a necessidade construída pelos especialistas e autoridades governamentais de cursos de formação continuada que "preencham a falta de teoria visualizada nos muitos problemas de ensino e aprendizagem que assolam a rede pública de ensino" (CARMAGNANI, 2013, p. 122).

Nesse tipo de discurso, observamos a presença de uma prática de objetivação pela comparação. Em trechos publicados da revista Veja sobre o tema educação, a voz de um especialista estrangeiro é evidenciada pela avaliação das escolas brasileiras em que o especialista expõe seu ponto de vista sempre comparando, de forma indireta, o ensino/a escola brasileira com os Estados Unidos, relegando a primeira a uma posição de inferioridade e a segunda de superioridade.

Em várias ocorrências, o especialista enfatiza que os problemas enfrentados só acontecem no Brasil, nos fazendo inferir sobre o não-dito ${ }^{3}$ que, ele na posição de especialista compreende como realmente deveria ser o ensino, nesse caso, igual à realidade do ensino dos Estados Unidos. Isso fica evidente se observamos os trechos a seguir: “... E o Brasil não conta com esse time de professores de alto padrão. Ao contrário. O nível geral é muito baixo" (p. 119), "Falta ao Brasil entender o básico" (p. 120), “O Brasil precisa, afinal, começar a se nivelar por cima” (p. 125), “... no Brasil ninguém sabe o que eles (os professores) estão ensinando em sala de aula" (p. 126).

Como podemos observar, há um movimento discursivo que instala a comparação como mecanismo de subjetivação. Cada vez que o especialista inicia sua enunciação com o termo Brasil, ele atribui as características que aparentam ser exclusivas de nosso país e, contrárias aos Estados Unidos. Depreende-se, portanto, que uma vez que o Brasil não atinge os mesmos critérios de qualidade, caracteriza-se pelo fracasso no ensino. Surge, portanto, a partir do exposto, duas posições distintas

\footnotetext{
${ }^{3}$ Entende-se que os sentidos podem ser lidos num texto mesmo não estando nele, de forma explícita. É importante se considerar tanto o que o texto diz quanto o que ele não diz, ou seja, o que está implícito, que não é dito, mas é significado.
} 


\section{Revista Letras Raras}

ISSN: 2317-2347 - Vol, 7, Ano 4, N0 2 - 2015

sujeitas à identificação: a do ensino de qualidade, que remete ao professor estrangeiro, "de alto padrão", e que "entende o básico e nivela por cima" e a do ensino de baixo nível, e a contrária, que remete aos professores brasileiros por não possuírem tais características.

Contrariamente, o discurso político-educacional traz evidências de um sujeito ideal, caracterizado principalmente pela conduta reflexiva: "o professor idealizado reflete sobre a aula, a partir de teorias modernas e o resultado seria a aprendizagem (sem conflitos) da língua estrangeira" (CARMAGNANI, 2013, p. 131).

Os estudos de Carmagnani (2013) apontam, portanto para duas caracterizações distintas do sujeito professor: o sujeito lacunado evidenciado pelo discurso midiático: “o discurso do fracasso, da mediocridade e má qualificação dos professores" e o sujeito ideal (reflexivo) evidenciado pelo discurso políticoeducacional: "o discurso do sucesso, da qualidade de ensino, dos profissionais engajados e desejosos de aprimoramento" (op. cit., p. 134).

No discurso político-educacional, identificamos uma prática de objetivação pela disciplinarização. As OCEM, segundo Carmagnani (2013), idealizam a sala de aula, e ao mesmo tempo, novas formas de controle do professor, de modo que lhes impõem uma posição subjetiva que deve ser ocupada: a do professor reflexivo. Conforme Grigoletto (2007), os compêndios político-educacionais sobre políticas de ensino, didática e metodologia, exercem o poder disciplinar por apresentarem dispositivos pedagógicos de controle. Ou seja, ao ressaltarem que uso da autonomia e reflexão em sala de aula são finalidades atribuídas como uma "instrução" a ser seguida, evidenciando um discurso de forte tendência ao controle e disciplinarização de professores à medida que molda o sujeito para agir conforme seus padrões de comportamento e pensamento.

Na sequência, analisamos o estudo de Costa (2013), que tem como objetivo contribuir com a discussão acerca da formação de professores de inglês, problematizando-a e buscando provocar os sujeitos envolvidos em tal processo 


\section{Revista Letras Raras}

ISSN: 2317-2347 - Vol. 7, Ano 4, No 2 - 2015

formativo a rever alguns modos com os quais se refere à formação docente (linguísticos e discursivos) em especial, do futuro professor de inglês.

O mecanismo analítico utilizado pelo autor tem como base a negação polêmica ${ }^{4}$ observada no discurso didático pedagógico, em entrevistas realizadas com alunos do curso de licenciatura em Letras, e com professores-formadores do mesmo curso.

Em análise, o pesquisador constatou por meio da negação polêmica, um efeito rebaixador ${ }^{5}$, devido a não execução das ações e à falta de preparo dos alunos do curso de Letras: "olha... eu tenho falhas nesse conteúdo... eu não vi isso... eu não li essa obra..." (COSTA, 2013, p. 194). Desse modo, os professores-formadores esboçaram o perfil de um aluno pautado na ausência (de interesse, maturidade, engajamento, etc), e na falta de preparo, além da falta de conhecimento (linguístico ou literário):

[...] as vezes me dá ... um pouco de medo... do conhecimento linguístico que esse aluno tem para passar para os futuros alunos deles... [...] eu acho que falta... uma... acho que falta uma base mais sólida... linguística..."(COSTA, 2013, p. 201, grifos do autor).

Ou seja, o discurso didático-pedagógico evidencia o perfil de um aluno que apresenta lacunas, principalmente no que diz respeito à competência linguística.

Nas entrevistas realizadas, observamos a presença de processos de objetivação pela comparação do aluno do curso de Letras a um aluno/professor ideal. Surgem, portanto, duas posições subjetivas a serem ocupadas: a do professor ideal, sem faltas, e a do professor constituído pela falta. Em seus relatos os professores-formadores reforçam a dificuldade dos alunos em relação aos conteúdos, ao desânimo, a precariedade da formação, a falta de leitura, de escrita e de base linguística, que é contrária ao que se é esperado desses futuros professores: "eu vejo

\footnotetext{
${ }^{4}$ Conceito com base em Ducrot (1987) trata-se de um efeito "rebaixador", pois é uma negação ou refutação de uma fala anterior (COSTA, 2013).

${ }^{5}$ Negação ou refutação de uma fala anterior (COSTA, 2013).
} 


\section{Revista Letras Raras}

ISSN: 2317-2347 - Vol. 7, Ano 4, N0 2 - 2015

o aluno um pouco perdido... primeiro... porque ele tem muita dificuldade em relação a conteúdos [...] não só perdidos... desanimados também [...]" (op. cit., p. 194). Esses professores em formação, portanto, não seguem o ideal que lhe é esperado, de dominação de conteúdos e ânimo, ao contrário, caracterizam-se pela ausência de ambos.

Dessa forma, o sujeito professor é constituído pela objetivação de um sujeito ideal que não existe, pois ao ser comparado com esse ideal, ele apresenta uma sequência de faltas que não o permite igualar-se àquilo que os professoresformadores esperam que ele seja.

Por fim, o estudo de Motta e Payer (2013) tem como objetivo propor e refletir sobre experiências, teoricamente sustentadas, de aulas de língua inglesa, acompanhando atentamente a sua realização, analisando e compreendendo pontos de relação entre sujeito, língua estrangeira e as atividades e linguagem que os enlaçam nas práticas de linguagem, no contexto de ensino-aprendizagem formal.

O mecanismo analítico utilizado pelas pesquisadoras é o funcionamento da memória no ensino da língua estrangeira, tendo como base o discurso de ensinoaprendizagem de língua.

$\mathrm{Na}$ análise de textos produzidos em sala de aula, as autoras constataram um sujeito constituído pela falta de memória discursiva que se apresenta como sinônimo de uma falta de conhecimentos linguísticos que permite a comunicação na língua inglesa. Vale ressaltar que esse sujeito tem o desejo de domínio comunicativo em Língua Inglesa, que se contrapõe à falta que lhe constitui, e acaba por gerar certa angústia:

Há que se considerar ainda, em relação a essa angústia, ligada a memória, que às vezes os sujeitos criam enunciados e significações que não estão relacionados a seus desejos de expressão como sujeitos efetivos de linguagem, enunciados e significações que são limitados no recurso da memória do dizer já disponível da/na língua alvo (MOTTA; PAYER, 2013, p. 259-260). 


\section{Revista Letras Raras}

ISSN: 2317-2347 - Vol. 7, Ano 4, No 2 - 2015

A angústia se dá, portanto, pelo impedimento de expressão enquanto sujeito efetivo de linguagem, que pode ser evidenciado pelo total silenciamento do sujeito, ou pela produção de enunciados e significações que não correspondem exatamente àquilo que ele gostaria de expressar. São esses resultados da limitação da memória na língua-alvo que acabam por agregar um sentimento de angústia à constituição do sujeito da falta.

Os alunos de Letras que foram investigados nesse estudo, passaram por um processo de objetivação por meio da comparação. A comparação se deu por meio da análise de poemas escritos pelos alunos, em que eles foram considerados como possuidores de uma memória representada ${ }^{6}$ da Língua estrangeira e foram comparados àqueles que possuem uma memória constitutiva ${ }^{7}$ da mesma, abrindo mais uma vez a possibilidade de duas posições subjetivas a serem ocupadas.

$\mathrm{Na}$ análise de dois poemas produzidos por alunos diferentes do curso de Letras, as pesquisadoras mostram que nenhum deles apresenta a memória constitutiva da/na língua estrangeira, embora estejam caminhando para essa constituição. Aluno 1: “a memória da língua-alvo está sendo construída e o sujeito parece estar enfrentando as diferenças e se inscrevendo na língua outra" (MOTTA; PAYER, p. 264, 2013) e aluno 2: “...parece-nos que a aluna não dispõe de memórias discursivas em língua inglesa suficientes para chegar até a conclusão do poema com palavras"(ibid., p. 267). Assim, nenhum deles apresenta memória discursiva suficiente para que se caracterize como memória constitutiva na língua estrangeira, característica essa que é evidenciada por alguns erros cometidos na produção do poema pelos alunos ou pela própria ausência de palavras.

\subsection{Objetivação pela disciplinarização}

\footnotetext{
${ }^{6}$ Memória raciocinada com visualização de estruturas. (MOTTA; PAYER, 2013).

${ }^{7}$ As formas linguísticas são expostas como tais, como saberes para o sujeito, tornando-se evidências de linguagem.(MOTTA; PAYER, 2013).
} 
Iniciamos a análise desse processo de objetivação com o estudo de Lopes (2013), que tem como objetivo lançar um desafio: a de que professores e alunos busquem se tornar mais criticamente conectados com suas formas locais de saber (herdadas e construídas) mantendo sempre aberta a possibilidade de dialogar e lidar, sem garantia de resultados, com o conflito.

Esse estudo se diferencia dos demais, por ser de natureza ensaística, não envolvendo sujeitos de pesquisa. Em seu trabalho, Lopes traz a concepção de pedagogia do conflito, que se define por trazer o conflito como centro da experiência, ou seja, como ponto de partida para uma oportunidade de mudança ou investimento pedagógico. Essa proposta visa uma prática dialógica em prol da transformação. Através do diálogo acredita-se ser possível a transformação do saber, uma vez que cada indivíduo traz uma contribuição indispensável e única. Sendo assim, constrói-se uma concepção de sujeito que se constitui pela reflexão e pela crítica por meio do diálogo.

A escola é tida como palco da performance reflexiva, em que o conflito não é visto como problema e sim como fonte de problematização e reestruturação do saberes que sustentam as práticas e geram diálogos. A pedagogia do conflito permite, portanto, a autorreflexão através do reexame de saberes e das trocas de conhecimentos, oferecendo uma oportunidade de apreender e transformar a partir do diálogo cooperativo:

[...] uma visão de conhecimento como co-construção, por parte dos sujeitos situados, uma pedagogia do conflito propicia o reexame constante dos saberes em termos de seus limites enquanto valorizada e verticalmente transmitida aos estudantes (LOPES, 2013, p. 172).

Apesar de não apresentar resultados com base em dados de análise, o trabalho do pesquisador traz algumas implicações para a formação de professores e para constituição do sujeito professor de inglês, oferecendo-lhe mais uma posição a 


\section{Revista Letras Raras}

ISSN: 2317-2347 - Vol. 7, Ano 4, No 2 - 2015

ser ocupada: a do professor que lida com a pedagogia do conflito. Por meio dessa pedagogia emerge-se um sujeito professor que vê o conflito com um olhar diferente, e a partir dele modifica sua prática com base na troca e transformação de saberes, por meio da reflexão e da crítica.

Por meio dessa proposta, o pesquisador apresenta técnicas de vigilância que caracterizam a constituição do sujeito pela disciplinarização que visa o controle e disciplinarização dos sujeitos moldados para agir de acordo com determinados padrões de comportamento e pensamento (GRIGOLETTO, 2007), que, no caso dessa pesquisa, é de acordo com a pedagogia do conflito; mudando suas atitudes, suas concepções, e sua prática em prol dessa pedagogia, tornando o conflito: “... autorreflexivamente, fonte de uma problematização e reestruturação dos saberes" que sustentam suas práticas (LOPES, p. 171, 2013).

Em seguida, analisamos o estudo de Braga (2013) que tem como objetivo estudar o controle homogeneizante no discurso pedagógico instrucional que, de acordo com a perspectiva da autora, estabiliza representações, uma vez que rejeita o diferente e a singularidade do sujeito, reproduzindo sujeitos que apenas repetem representações estabilizadas e se assujeitam a elas.

O mecanismo analítico utilizado pela pesquisadora foi o estudo do controle homogeneizante do discurso instrucional apresentado e refletido no discurso de ensino e aprendizagem, por meio de dizeres instrucionais em manuais do professor e em palestras de autores de apostilas didáticas para o ensino de inglês como língua estrangeira.

$\mathrm{Na}$ análise do discurso pedagógico instrucional, em dizeres de autores de materiais didáticos de inglês aos professores usuários desses materiais, a autora observou que o professor é tratado como uma "tábula rasa e passível à alienação" (BRAGA, 2013, p. 284).

Assim, apresenta-se um sujeito que é assujeitado ao discurso instrucional que: “... contribui ao processo de subjetivação caracterizado pela reprodução, pela 


\section{Revista Letras Raras}

ISSN: 2317-2347 - Vol. 7, Ano 4, N0 2 - 2015

repetição, e não favorece a subjetivação pela singularidade..." (BRAGA, 2013, p. 288), ou seja, um sujeito que mantêm a homogeneização que, segundo a autora, não apresenta importantes diferenças, nem se dispõe a deslocar as posições subjetivas do professor e do aluno. Isto é, impõe uma única posição subjetiva a ser seguida, pautada em uma identidade fixa, unificada e estável, contrária ao sujeito pósmoderno, que se caracteriza fundamentalmente pela fragmentação e instabilidade.

O discurso instrucional impõe sua própria representação de língua e não permite que o aluno se torne sujeito na língua do outro, passando somente a reproduzir aquilo que lhe foi imposto. É esse, portanto, um mecanismo de controle para "anular a possibilidade de falha e conter o sentido" (BRAGA, p. 282, 2004).

Dessa forma, reflete-se nesse estudo como uma prática de objetivação pela disciplinarização, que por meios de controle "tem como função a normatização e homogeneização de indivíduos" (GRIGOLETTO, 2007, p. 456), estabelecendo um "processo de adestramento de seus corpos e de seu espírito" (op. cit., p. 456). Ou seja, o discurso instrucional impõe para os sujeitos uma única representação de língua, como código, que deve ser seguida, impedindo a discordância e emergência da singularidade.

Por fim, analisamos o estudo de Fortes (2013) que tem como objetivo problematizar o funcionamento de alguns modos de dizer sobre o "erro" que emergem da relação ideologicamente marcada entre o discurso da cientificidade e o da divulgação científica instaurando posições subjetivas que muitas vezes excluem professores e aprendizes de processos singulares e dos conflitos envolvidos no encontro com a LE, tornando a transparência das línguas e de seu ensino como uma evidência para os sujeitos.

O mecanismo analítico utilizado pela pesquisadora foi o estudo do tratamento do erro, tendo como base o discurso científico e o discurso de ensino-aprendizagem, na análise de enunciados de sinopses de alguns textos de divulgação científica publicados no site da Editora Disal. 


\section{Revista Letras Raras}

ISSN: 2317-2347 - Vol. 7, Ano 4, No 2 - 2015

Nesse estudo, o professor e o aluno assumem a posição de leigo, ou seja, daquele que não sabe ou que pouco sabe. E o discurso de divulgação científica traz verdades a serem seguidas para o sucesso em práticas de ensino e aprendizagem através da "voz do cientista "simplificada" na forma de "estratégias, "técnicas"..." (FORTES, 2013, p. 313), entre outros.

Aparece, portanto um sujeito constituído pela falta de conhecimentos, que é incapaz de ler a teoria e por esse motivo busca por estratégias e/ou técnicas, que se tornam consumíveis. Essa busca é impulsionada pela objetivação do sujeito por meio da disciplinarização. Ao tratar do erro, o discurso de divulgação científica enfatiza a importância do uso de estratégias e técnicas que são "naturalizadas como verdades que deverão ser seguidas pelo professor e pelo aprendiz para que tenham sucesso em suas práticas de ensino e aprendizagem de língua estrangeira" (FORTES, 2013, p. 313). Essas verdades impostas são propagadas por um mecanismo de controle que visa, segundo Grigoletto (2007), promover a uniformização de conteúdos e métodos e, consequentemente, a homogeneização dos sujeitos que devem ocupar uma mesma posição subjetiva, nesse caso, a de consumidor dessas estratégias e técnicas.

\subsection{Técnicas de autoconhecimento}

Iniciamos a análise desse processo de objetivação com o estudo de Uyeno (2013) que tem como objetivo refletir sobre o saber epistemológico e o saber psicanalítico na formação continuada de professores, e entender o que leva um profissional experiente procurar voluntariamente cursos de formação continuada. A pesquisadora estudou o discurso didático-pedagógico, por meio de gravações de interações entre professores-alunos e a professora ministrante de um módulo em curso de especialização em leitura e produção de textos, oferecido por uma universidade pública de São Paulo. 


\section{Revista Letras Raras}

ISSN: 2317-2347 - Vol. 7, Ano 4, No 2 - 2015

$\mathrm{O}$ mecanismo de análise utilizado nessa pesquisa foi a escuta analítica, que abarca dois planos: a comunicação primitiva e a escuta das interpretações do analista. O primeiro plano, leva em consideração a comunicação não verbal, transmitida inconsciente, como a linguagem corporal, a linguagem oniróide (sonhos, devaneios) e a conduta do paciente. E o segundo plano, considerada a interpretação precisa do analista.

Percebemos nesse estudo que professores-alunos mostraram a proeminência da confissão de um não saber, em várias ocorrências, tais como: "Esse professor sou eu. Tenho muito a aprender sobre o assunto" (UYENO, 2013, p. 97); "Essas coisas todas que você está dizendo a gente não sabe" (UYENO, 2013, p. 103).

Ao analisar as gravações, percebemos o uso das técnicas de autoconhecimento, na medida em que a professora narra e reflete acerca da necessidade de cursos de aperfeiçoamento a fim de melhor executá-los e adquirir cada vez mais conhecimento. Vejamos isso em: "Os profissionais precisam estar constantemente em cursos de aperfeiçoamento e pesquisas, buscando adequar os objetivos da realidade dos alunos e do mundo, pois nunca se esgota" (UYENO, 2013, p. 99).

A falta de conhecimentos linguísticos emerge a partir do momento que, ao falarem de si mesmos, atendem a um princípio fundamental da modernidade, o de "conhecer a si mesmo", conforme afirma Grigoletto (2007). Esse princípio caracteriza o processo de subjetivação pelas técnicas de autoconhecimento, uma vez através da narração, da relação do sujeito consigo mesmo, ele pensa sobre si mesmo, e isso resulta em um processo de autosubjetivação.

Na sequência, analisamos o estudo de Passos (2013), que tem como objetivo examinar como professores de inglês, na escola pública estadual de São Paulo, concebem sua prática didático-pedagógica, e lançar um olhar sobre a questão da relação com o saber, ou seja, examinar a relação do sujeito professor com o 


\section{Revista Letras Raras}

ISSN: 2317-2347 - Vol. 7, Ano 4, N0 2 - 2015

conhecimento que ele acredita ter (ou não). Esses dizeres foram registrados por meio de entrevistas semiformais, na forma de depoimentos (narrativas orais).

O mecanismo analítico tem como base, portanto, a relação do sujeito professor com o saber e tem como fonte o discurso didático-pedagógico.

Ao estudar o discurso didático-pedagógico, observamos duas caracterizações distintas e conflitantes do sujeito professor: o sujeito do saber e o sujeito do não saber. Devido ao lugar social que ocupa, o professor aparece como aquele que deveria saber: "a associação entre os termos "professor/mestre" e "não saber" é desconcertante, causa estranhamento" (PASSOS, 2013, p.154). O reconhecimento da "obrigação" do professor de ser aquele que sabe, é evidenciado no momento em que os entrevistados demonstram sentimento de culpa por não se caracterizarem como esse sujeito e apontarem o conhecimento como equivalente a um dever ou dívida:

A lacuna é percebida ao mesmo tempo como dívida (culpa) para com o aluno e consigo própria, pois o aspecto do verbo em inglês, como conteúdo curricular a ser ensinado, no dizer da professora entrevistada, é algo que ela deveria - por exigência do lugar de professor de língua - ter assimilado (PASSOS, 2013, p. 160, grifo do autor).

Os entrevistados se assumem, portanto, como sujeitos do não saber: mal preparados, com bagagem intelectual insuficiente e fluência precária no idioma, ou seja, constituídos pela falta. Ao ponto que os sujeitos descrevem-se, narram-se e analisam-se, torna-se evidente que, nesse estudo, apresentam-se práticas de subjetivação por meio das técnicas de autoconhecimento. Conforme afirma Grigoletto (2007, p. 458): "nesse processo de autorreflexão, o aluno é colocado na posição de narrador de si mesmo e das suas práticas e de avaliador de seu aprendizado".

Vejamos um dos excertos abordados no estudo de Passos, em que fica evidente o processo de narração e reflexão: 


\section{Revista Letras Raras}

ISSN: 2317-2347 - Vol, 7, Ano 4, N0 2 - 2015

eu acho que dando aula... foi quando eu percebi algumas limitações que eu tinha e que de repente como aluna eu não via/ eu ia preparar uma coisa/ eu falava " pôxa, mas isso eu não sei direito"/ e dai eu tinha que ir atrás / e aí eu comecei a ver o quanto eu precisava aprender ainda / que eu não sabia ... (PASSOS, 2013, p. 159).

Como podemos observar, o professor expôs sua própria experiência docente, através da narração, colocando sua prática como aquilo que o permitiu reconhecer suas limitações, ou seja, sua falta de conhecimentos linguísticos e ao mesmo tempo o fator que o/a impulsionou para ir em busca do preenchimento dessa falta, a partir do estudo e aprendizado. Houve, portanto, não somente a descrição, mas também um processo de reflexão e avaliação de sua prática docente. A esse processo, Foucault denomina como o uso das técnicas de si.

Em seguida, analisamos o estudo de Andrade (2013) que tem como objetivo contribuir para a discussão sobre o que significa ensinar e aprender uma língua estrangeira e o modo como essa língua e essa aprendizagem incidem na constituição identitária do sujeito professor e do sujeito aluno.

O mecanismo analítico utilizado pela pesquisadora é a construção narrativa e tem como base os discursos didático-pedagógico e mercadológico.

Através de entrevistas orais realizadas com alunos do último ano de um curso de licenciatura dupla (inglês/português), estudaram-se narrativas ficcionais produzidas por meio de elementos provenientes da memória do falante, constituída por imagens recortadas que o narrador seleciona a partir do uso das "tecnologias da memória" que são, portanto, formas de agenciar lembranças.

A pesquisadora observou no discurso didático-pedagógico, dois tipos de sujeito: o sujeito do desejo, e o sujeito consumidor, ambos constituídos pela falta. $\mathrm{O}$ sujeito do desejo aparece como aquele que tem o desejo de ser na língua do outro e se constrói pela sensação de falta que persegue o sujeito em qualquer língua: “... a língua estrangeira (e a cultura que a envolve) é imaginada como um lugar identitário 


\section{Revista Letras Raras}

ISSN: 2317-2347 - Vol. 7, Ano 4, No 2 - 2015

desejado: o sujeito quer estar na língua e na cultura do outro, quer "possuir" a língua para si" (ANDRADE, 2013, p. 226-227).

E o sujeito consumidor, que emerge pelo viés do discurso mercadológico, é aquele que surge em consequência do sujeito desejante (na lógica capitalista) e que busca suprir a falta através de habilidades, técnicas, e métodos, que se oferecem de LE para o aprendizado. Assim, estas "várias habilidades" acabam por desempenhar o papel de mercadorias oferecidas ao consumidor, para o tamponamento da falta constitutiva desse sujeito, o sujeito professor, que se vê sempre em desamparo.

Nas entrevistas orais, observamos a presença de práticas de subjetivação por meio das técnicas de autoconhecimento e isso é inclusive evidenciado pela própria autora quando afirma: "à medida que os alunos-professores punham-se a falar sobre suas experiências com as línguas, notamos, ainda, que a pergunta proposta surgia como pretexto para a construção de uma narrativa sobre si" (ANDRADE, 2013, p. 222). Há, portanto, conforme afirma Grigoletto (2007), a narração a si mesmo, de suas práticas e o sujeito professor também se torna avaliador do seu próprio aprendizado.

\section{CONSIDERAÇÕES FINAIS}

Observamos, no estudo das categorias analíticas dos nove textos mencionados anteriormente, que cada um deles evidencia seus resultados por meio de categorias de análise distintas. Entretanto, no que diz respeito ao modo como o sujeito professor é visto, há uma predominância, por meio de diversos discursos (didáticopedagógico, ensino-aprendizagem, científico, político educacional e instrucional) de um professor, pré ou em serviço, constituído principalmente pela falta (de preparo, de conhecimentos linguísticos e/ou teóricos, de prática, etc.).

Verificamos que os três modos de objetivação que nos tornam sujeitos apareceram presentes em nossa análise. Segundo Grigoletto (2007), a objetivação do sujeito seja pela comparação ou pela disciplinarização, traçam uma posição de sujeito desejante, uma vez que este é constituído pela falta. É, portanto, um sujeito que não 


\section{Revista Letras Raras}

ISSN: 2317-2347 - Vol. 7, Ano 4, No 2 - 2015

consegue se igualar ao "outro" e está sempre assumindo uma posição inferior a ele em um movimento de comparação constante, e é também um sujeito que precisa seguir as regras disciplinarizantes de controle, e por este motivo tem que agir de acordo com os padrões de uniformização de conteúdos, técnicas, procedimentos didáticos e metodológicos o que leva a recorrência do discurso da falta, na busca incessante da homogeneização que essa objetivação busca, e que se reflete com muita frequência nos dizeres de professores de inglês.

Como podemos observar na análise, os processos de comparação propõem sempre duas posições subjetivas distintas, a que o professor já ocupa e que está sempre associada a essa falta que lhe constitui, e outra, contrária, em que essas faltas não existem, e que lhe parece impossível de ocupar ou se identificar. A disciplinarização por outro lado, traça apenas uma posição subjetiva que deve ser seguida por meio do controle e da busca da homogeneização dos indivíduos que levam a uma identidade fixa, unificada e estável - divergindo da concepção de sujeito pós-moderno caracterizado pela fragmentação e instabilidade.

Ressaltamos que, embora Grigoletto (2007) mencione apenas a disciplinarização e a comparação como delineadoras de posições sujeito desejantes e constituídos pela falta, observamos em nosso estudo esse mesmo processo de subjetivação, também, nas tecnologias de autoconhecimento. Isso acontece, possivelmente, porque apesar do sujeito estar fazendo uso das técnicas de si, não deixa de sofrer direta ou indiretamente a influência da disciplinarização e da comparação que são reforçados pelos diferentes discursos (politico educacional, instrucional, etc.) que lhes cercam, fazendo com que esses reproduzam o discurso da falta ao narrarem, analisarem e refletirem sobre si mesmos.

A falta está diretamente relacionada à constituição da identidade. Segundo Hall (2006), as identidades modernas estão sendo deslocadas ou fragmentadas, isto é, o indivíduo moderno não é mais visto como um sujeito unificado, e é por isso que o autor afirma que não devemos falar em identidade como algo acabado, mas sim 


\section{Revista Letras Raras}

ISSN: 2317-2347 - Vol. 7, Ano 4, N0 2 - 2015

como um processo em andamento, por isso é melhor falar em identificação, uma vez que, como afirma Woodward (2000) existe, na vida moderna, uma série de posições que nos estão disponíveis e que podemos ocupar e a própria vida moderna exige que assumamos diferentes identidades. Conforme Hall (2006, p. 39), "nós continuamos buscando a "identidade" e construindo biografias que tecem as diferentes partes de nossos eus divididos numa unidade porque procuramos recapturar esse prazer fantasiado de plenitude", ou seja, a identidade surge pela busca de plenitude diante da falta constitutiva, que precisa ser preenchida. Por meio desses processos de objetivação/subjetivação do sujeito professor de inglês apresentados neste estudo, percebe-se também essa busca pela completude, entretanto, o sujeito encontra-se em uma posição de restrição ao processo constante de transformação, em que ele assumiria identidades diferentes, em diferentes momentos.

\section{REFERÊNCIAS BIBLIOGRÁFICAS}

ANDRADE, E. R. In: CARMAGNANI, A. M. G.; GRIGOLETTO, M. (Org.). Língua, discurso e processos de subjetivação na contemporaneidade. São Paulo: Humanitas, 2013, p. 209-242.

BRAGA, M. D. W. In: CARMAGNANI, A. M. G.; GRIGOLETTO, M. (Org.). Língua, discurso e processos de subjetivação na contemporaneidade. São Paulo: Humanitas, 2013, p. 273-292.

BRANDÃO, H. H. N. Introdução à análise do discurso. 3. ed. rev. Campinas: Ed. Da UNICAMP, 2012.

CARMAGNANI, A. M. G. In: CARMAGNANI, A. M. G.; GRIGOLETTO, M. (Org.). Língua, discurso e processos de subjetivação na contemporaneidade. São Paulo: Humanitas, 2013, p. 113-142.

CARMAGNANI, A. M. G.; GRIGOLETTO, M. (Org.). Língua, discurso e processos de subjetivação na contemporaneidade. São Paulo: Humanitas, 2013.

CHARAUDEAU, P.; MAINGUENEAU, D. Dicionário de análise do discurso. São Paulo: Contexto, 2004. 


\section{Revista Letras Raras}

ISSN: 2317-2347 - Vol, 7, Ano 4, N0 2 - 2015

CORACINI, M. J.; GHIRALDELO, C. M. (Org.). Nas malhas do discurso: memória, imaginário e subjetividade. Campinas: Pontes, 2011.

COSTA, M. A. M. In: CARMAGNANI, A. M. G.; GRIGOLETTO, M. (Org.). Língua, discurso e processos de subjetivação na contemporaneidade. São Paulo: Humanitas, 2013, p. 187-206.

FORTES, L. In: CARMAGNANI, A. M. G.; GRIGOLETTO, M. (Org.). Lingua, discurso e processos de subjetivação na contemporaneidade. São Paulo: Humanitas, 2013, p. 293319.

FOUCAULT, M. A ordem do discurso. 14. ed. São Paulo: Loyola, 2005. . Vigiar e punir: nascimento da prisão. 27. ed. Petrópolis: Vozes, 2003.

GRIGOLETTO, M. Um saber sobre os sujeitos: Práticas de subjetivação no discurso políticoeducacional sobre línguas estrangeiras. Claritas (PUCSP), v. 9, p. 45-55, 2007.

HALL, S. A identidade cultural na pós-modernidade. 11 ed. Rio de Janeiro: DP\&A Editora, 2006.

LOPES, C. R. In: CARMAGNANI, A. M. G.; GRIGOLETTO, M. (Org.). Lingua, discurso e processos de subjetivação na contemporaneidade. São Paulo: Humanitas, 2013, p. 163-186.

MAGALHÃES, I. et al. (Org.). Práticas identitárias: língua e discurso. São Carlos:Claraluz, 2006.

MEDRADO, B. P.; REICHMANN, C. L. (Org.). Projetos e práticas na formação de professores de língua inglesa. João Pessoa: Editora da UFPB, 2012. 231 p.

MITTMANN, S. et al. (Org.). Práticas discursivas e identitárias: sujeito e língua. Porto Alegre: Nova Prova, 2008.

MOTTA, V. R. A. ; PAYER, M. O. In: CARMAGNANI, A. M. G.; GRIGOLETTO, M. (Org.). Lingua, discurso e processos de subjetivação na contemporaneidade. São Paulo: Humanitas, 2013, p. 243-272.

NEVES, K; NASCIMENTO, W. F. Technologies of the self (Université du Vermont, outubro, 1982; trad. F. Durant-Bogaert). In: Hutton (P.H.), Gutman (H.) e Martin (L.H.), ed. Technologies of the Self. A Seminar with Michel Foucault. Anherst: The University of Massachusetts Press, 1988, pp. 16-49. Traduzido a partir de FOUCAULT, Michel. Dits et écrits. Paris: Gallimard, 1994, Vol. IV, pp. 783-813, por Karla Neves e Wanderson Flor do Nascimento. 
ORLANDI, E. P. Análise de discurso: princípios e procedimentos. 5. ed. Campinas: Pontes, 2005.

. A linguagem e seu funcionamento: as formas do discurso. 4. ed. Campinas:

Pontes,2006.

. As formas do silêncio: no movimento dos sentidos. 6. ed. Campinas: Ed. da UNICAMP, 2007.

PASSOS, D. M. S. P. In: CARMAGNANI, A. M. G.; GRIGOLETTO, M. (Org.). Língua, discurso e processos de subjetivação na contemporaneidade. São Paulo: Humanitas, 2013, p. 143-162.

PÊCHEUX, M. Semântica e discurso: uma crítica à afirmação do óbvio. 4. ed. Campinas: Ed. da UNICAMP, 2009.

WOODWARD, K. In: SILVA, T.T. Identidade e diferença a perspectiva dos estudos culturais/ Tomaz Tadeu da Silva (org). Stuart Hall, Kathryn Woodward. - Petrópolis, RJ: vozes, 2000.

Recebido em: 31 de agosto de 2015

Aceito: em 27 de outubro de 2015 